Original article

\title{
Combinations of dietary calcium intake and mediterranean-style diet on risk of hip fracture: A longitudinal cohort study of 82,000 women and men
}

\author{
Eva Warensjö Lemming ${ }^{\text {a, }}{ }^{*}$, Liisa Byberg ${ }^{a}$, Jonas Höijer ${ }^{a}$, Susanna C. Larsson ${ }^{\text {a, b }}$, \\ Alicja Wolk ${ }^{\mathrm{a}, \mathrm{b}}$, Karl Michaëlsson ${ }^{\text {a }}$ \\ ${ }^{a}$ Department of Surgical Sciences, Section of Orthopedics, Uppsala University, Uppsala, Sweden \\ ${ }^{\mathrm{b}}$ Unit of Cardiovascular and Nutritional Epidemiology, Institute of Environmental Medicine, Karolinska Institutet, Stockholm, Sweden
}

\section{A R T I C L E I N F O}

\section{Article history:}

Received 31 January 2020

Accepted 28 January 2021

\section{Keywords:}

Calcium

Mediterranean-style diet

Hip fracture

Cohort study

Epidemiology

Nutrition

\begin{abstract}
S U M M A R Y
Background and aims: Each year, millions of people suffer from fragility fractures. Hip fractures are the most devastating type of such fractures. We aimed to investigate whether the association of dietary calcium intake with hip fracture risk can be modified by a healthy diet, herein defined as the modified Mediterranean diet score (mMED), in Swedish adults.

Methods: The study included 82,092 men and women at baseline. Diet and covariate data were collected twice, 12 years apart, using questionnaires. Information on incident hip fractures was collected from a national registry. Dietary calcium intake and mMED were each categorized into low, medium and high categories, and in nine combined strata of the two exposures. Multivariable adjusted hazard ratios (HR) of hip fracture with 95\% confidence intervals (CI) were calculated using Cox proportional hazards regression analysis, with time-updated information on exposures and covariates. Non-linear trends were assessed using restricted cubic splines.

Results: During 20 years of follow-up including 1,367,260 person-years at risk, 5938 individuals experienced a hip fracture. Dietary calcium intake and hip fracture were non-linearly associated, whereas adherence to mMED decreased hip fracture rates in a dose-response pattern. The lowest hip fracture rates were observed among women and men who reported a calcium intake of 800 mg or more, combined with a high adherence to mMED. In each stratum of calcium intake, the HRs of hip fracture were increasingly higher with lower adherence to mMED, compared with the reference level (high calcium and high mMED). Individuals with low calcium intake ( $<800 \mathrm{mg} /$ day) or high calcium intake $(>1200 \mathrm{mg} /$ day) combined with low adherence to mMED had a HR of 1.54 (95\% CI 1.28-1.85) and 1.50 (95\% CI 1.26 $-1.77)$, respectively. No major differences in the hip fracture risk patterns were discerned between women and men.

Conclusion: A moderate to high dietary calcium intake in the context of an overall healthy diet were associated with lower hip fracture rates.
\end{abstract}

(C) 2021 The Authors. Published by Elsevier Ltd. This is an open access article under the CC BY license (http://creativecommons.org/licenses/by/4.0/).

\section{Introduction}

Each year, millions of people throughout the world suffer from fragility fractures [1]. Hip fractures are the most devastating type of fractures and are associated with high burden of morbidity, healthcare costs and mortality [2]. Worldwide, about one in five

\footnotetext{
* Corresponding author. Department of Surgical Sciences, Section of Orthopedics, Uppsala University. MTC/Epihubben, Dag Hammarskjölds väg 14B, Uppsala Science Park, SE- 75183 Uppsala. Sweden.

E-mail address: eva.warensjo.lemming@surgsci.uu.se (E. Warensjö Lemming).
}

women and one in ten men will suffer from a hip fracture in their lifetime [3].

Adequate dietary intake of calcium is vital for continuous bone homeostasis and is promoted for the prevention of osteoporosis and fractures [4,5], but the adequate level of calcium intake has long been debated [6-8]. Recent systematic reviews and meta-analyses have concluded that neither dietary calcium, nor short-term supplementation with calcium (alone or in combination with vitamin $\mathrm{D}$ ), help in the primary prevention of fractures $[9,10]$ in the general population. The optimal level of calcium intake to maintain a healthy skeleton therefore remains to be clarified [11]. 
In the last decade, the importance of a healthy diet for the prevention of fragility fractures has been emphasised. A healthy diet seems to have a crucial role in preventing osteoporosis, and many nutrients and bioactive components may be important $[12,13]$. For instance, adherence to a Mediterranean-style diet $[14,15]$, other healthy dietary patterns [16-18] and high intake of fruits and vegetables $[19,20]$ are inversely associated with the risk of fractures in different population settings [14-20].

We aimed to study whether the increased risk of hip fracture, associated with low calcium intake in Swedish adults, could be modified by adherence to a healthy diet, herein defined as the modified Mediterranean diet (MMED). We hypothesise that both a high intake of calcium and a healthy diet would be optimal for prevention of hip fractures. We will therefore extend our prior work on dietary calcium and Mediterranean diet [15,18], by examining the associations of a low, moderate and high calcium intake with risk of hip fracture at different levels of adherence to mMED.

Our overall objective is to determine the separate and combined associations between calcium intake, dietary healthfulness and the risk of hip fracture, using data from two longitudinal cohorts of 82,092 Swedish women and men between 1997 and 2017.

\section{Materials and methods}

\subsection{Study cohorts}

The study population consisted of participants from two population-based cohort studies: The Swedish Mammography Cohort (SMC) and the Cohort of Swedish Men (COSM), which are both part of the national research infrastructure SIMPLER (www. simpler4health.se/). SMC was established in 1987-1990. All women born between 1914 and 1948, residing in two Swedish counties (Uppsala and Västmanland), were invited to a mammography screening $(n=90,303)$. Enclosed with this invitation was a questionnaire covering diet and lifestyle, which was completed by $74 \%$ of the women. In fall 1997, a second extended questionnaire was sent to all SMC participants $(n=56,030)$ who were still alive. COSM was established in late 1997. All male residents ( $n=100,303$ ), of two Swedish counties (Örebro and Västmanland), born between 1918 and 1958, were invited to participate. The questionnaire that was distributed in late 1997 in both cohorts was identical, except for the sex-specific questions. The questionnaire included almost 350 items including diet (food frequency questionnaire; FFQ) and other lifestyle factors, for example, sociodemographic data, weight, height, waist and hip circumference, physical activity and exercise, self-perceived health status, smoking status, alcohol consumption and use of dietary supplements. The questionnaire was completed by 70 per cent of the women and by 49 per cent of the men. The final cohort consisted of 84,334 individuals, including 38,984 women from the SMC and 45,906 men from the COSM. The study sample at baseline (1 January 1998) in the present study excluded participants if their energy intake was deemed as implausible $( \pm 3$ SD from the mean value of the lntransformed energy intake), or if they had a prior cancer diagnosis (except non-melanoma skin cancer) and consisted of 82,092 individuals. In late 2008, a questionnaire covering the general health status, lifestyle and diseases was sent out to all participants, who were still alive, living in the study area and had completed the 1987-90 (SMC) and 1997 (COSM) questionnaires. The response rate was 63 per cent in SMC and 78 per cent in COSM. Those who responded to the 2008 questionnaire received an expanded FFQ in 2009 , and the response rate was 84 per cent in SMC and 90 per cent in COSM. The final cohorts in 2009 consisted of 24,199 women in SMC and 29,367 men in COSM. The study was approved by the regional ethics committees at Uppsala University, Uppsala, and Karolinska Institutet, Stockholm, Sweden.

\subsection{Dietary assessment and food groupings}

The dietary assessment has been described previously [21]. Briefly, the FFQs included 96 and 132 food items in 1997 and 2009, respectively. Participants indicated in the FFQs how often, on average, they had consumed each food item during the last year and chose from 8 predefined frequency categories, ranging from "never/seldom" to "3 or more times per day" (1997 FFQ). Frequently consumed foods such as dairy products and bread were additionally reported as number of servings per day. Information on fat type used in cooking and as salad dressing was also reported. Total amount of alcohol consumed per day was derived from the FFQ by multiplying the reported frequency with the reported amount on a single occasion. Energy and nutrient intakes were estimated by multiplying the consumption frequency of each food item with the energy and nutrient content of age-specific portion sizes for each food. Energy and nutrient values were obtained from the Swedish food composition database, Swedish Food Agency. Nutrient intakes were adjusted for total energy intake using the residual method [22].

\subsection{Exposures}

\subsubsection{Calcium intake}

The main exposure in the present study is the energy residual adjusted intake of dietary calcium, treated as a continuous and categorical variable. The intake of dietary calcium does not include calcium from calcium supplements or multivitamins with minerals. The three categories of calcium were pre-specified and as follows: low ( $\leq 799 \mathrm{mg})$, medium (800-1199 mg) and high ( $\geq 1200 \mathrm{mg}$ ). Calcium intake in the $1997 \mathrm{FFQ}$ correlated well with estimates from 14 repeated 24-h recalls over 1 year in men $(r=0.77)$ [23]. An additional validation study of SMC showed that calcium intake correlated well between the FFQ and four 7-day food records $(\mathrm{r}=0.72)$ [18]. The average difference in dietary calcium intake between the 1997 food frequency questionnaire and the food records was $56.4 \mathrm{mg} /$ day (95\% confidence interval 4.4 to 108.4), which is a tendency of higher reported intake with the food frequency method [24].

\subsection{Modified mediterranean diet score}

Adapted from the Mediterranean diet scale by Trichopoulou et al. [25], a modified Mediterranean diet score (mMED) was calculated by using previously defined food items [26]. Participants with higher score points were considered as being more adherent to the diet score. The calculation of the diet score in the present study is a modification of the mMED score, according to a method described by Knudsen et al. [27]. An individual with a reported intake above or below a specific cut off point for each component of a diet score usually receives discrete score points ( 0 or 1 ); however, in the method described by Knudsen et al. [27], each individual receives 1 or a ratio between the actual intake and the chosen cut off point. Such an approach generates continuous component variables within the exposure width, which is an advantage in regression analyses. More information on the calculation of the mMED is found in the Supplemental material 1. A three level categorical mMED score was formed among the participants, with 0 $<4$ points indicating low adherence, $4-<6$ points medium adherence and 6-8 points high adherence, as previously suggested [28]. Both calcium intake and mMED were treated as time-updated variables, using data from both investigations. 


\subsection{Hip fracture ascertainment}

We considered outcomes registered between study baseline 1 January 1998 and 31 December 2017. Hip fracture cases were defined by the ICD10 codes S720, S721 and S722. Information on incident hip fracture events was obtained through individual linkage to the Swedish National Patient Registry [29] and by using a previously validated and accurate method [30]. The matching to the register was almost complete because of the unique identification number assigned to all Swedish permanent residents.

\subsection{Additional information}

We identified variables to be included as covariates in the multivariable adjusted models using present knowledge regarding diet-hip fracture associations, and the directed acyclic graphs method [31]. A directed acyclic graph illustrates the underlying assumptions of causal actions for the present research question (Supplemental Material 2). From the questionnaires, age, highest educational level, weight and height, use of multivitamins with or without minerals, calcium and vitamin D supplements, total energy intake, intakes of retinol, vitamin D and alcohol, cortisone use, smoking status, living alone, walking/cycling, and leisure time physical exercise during the past year, were included as covariates. Body Mass Index (BMI) was calculated as weight $(\mathrm{kg})$ divided by height squared $\left(\mathrm{m}^{2}\right)$. The physical exercise question has been found to be valid compared to activity records and accelerometer data [32]. We further included Charlson's weighted comorbidity index as a covariate since comorbid conditions are likely to influence both dietary intakes and fracture risk. The Charlson's weighted comorbidity index $[33,34]$ was defined based on in-patient treated occurrences from the National Patient Register of 17 different disease groups from 1964 through the day before the baseline, 1 January 1998.

\subsection{Statistical analysis}

For each participant, follow-up time was accrued from 1 January 1998 until date of a first hip fracture, date of death or the end of the study period (31 December 2017). The associations between dietary calcium intake, mMED and the combination of the two, and hip fracture were investigated as multivariable adjusted hazard ratios (HR) with 95\% confidence intervals (CI) using Cox proportional hazards regression models. All variables, except educational level and sex, were updated once at the time of the second questionnaire, and calendar date was used as the time scale. Dietary calcium and mMED were initially treated individually and as continuous variables to assess linear trends. Subsequently, the three level categorical variables (low, medium and high) of calcium and mMED were combined into nine strata that were investigated using Cox proportional hazard analysis with a joint reference category (high calcium and high mMED adherence). The non-linear trends of the association between each of the diet exposures and hip fracture risk were also assessed using restricted cubic-splines, with three knots placed at the 10th, 50th and 90th percentile of the continuous exposure, as recommended by Harrell [35]. In the analysis with calcium as the exposure, HRs were computed with the reference level set at $800 \mathrm{mg}$ of calcium, corresponding to the recommended intake for Swedish women $>50$ years [36]. In the analysis with mMED, the reference level was set at a score point of 8 . Two multivariable models were applied. The first model (Model 1) included sex and age (splines with three knots). The second multivariable model (Model 2) included sex, age (splines with three knots), educational level $(\leq 9,10-12,>12$ years, other), leisure time physical exercise during the past year ( $<1 \mathrm{~h} / \mathrm{w}, 1 \mathrm{~h} / \mathrm{w}, 2-3 \mathrm{~h} / \mathrm{w}$,
4-5 h/w, $>5 \mathrm{~h} / \mathrm{w}$ ), walking/cycling (almost never, $<20 \mathrm{~min} / \mathrm{d}$, 20-40 min/d, 40-60 min/d, 1-1.5 h/d,>1.5 h/d), living alone (yes or no), energy intake (splines with three knots), height (splines with three knots), BMI (splines with three knots), energy-adjusted intakes of retinol (splines with three knots), vitamin D (splines with three knots), and alcohol (splines with three knots), any use of calcium or vitamin D supplements (binary), cortisone use (binary), smoking habits (current, former, never) and Charlson's weighted comorbidity index (continuous). Linearity for splines was tested after each model, and non-linearity of the relations were confirmed. Missing data were imputed (20 imputations) using Stata's "mi" package (multiple imputations using chained equations). The multiple imputation takes into account model variables and produces 20 separate datasets. The Cox analysis is subsequently run on all the separate datasets and the results are combined [37]. The proportion of missing data in the cohort was $9.1 \%$ ( $\mathrm{n}=7542)$ for walking/cycling, $11.0 \%(\mathrm{n}=9161)$ for physical exercise, $2.8 \%(\mathrm{n}=2363)$ for height, $6.5 \%(\mathrm{n}=5408)$ for living alone and $3.9 \%(n=3202)$ for BMI. For all other covariates, the percentage of missing data was less than $2 \%$. Missingness at baseline of fruit and vegetables was $0.1 \%$, of legumes and nuts $3.4 \%$, grains $0.9 \%$, fermented dairy products $2.9 \%$, fish $1.1 \%$, meat $0.7 \%$, olive or rapeseed oil $0 \%$, and alcohol intake $0 \%$.

As a sensitivity analysis, we considered the potential competing risk problem from mortality by the method of Fine and Gray [38]. We first used complete case data (no imputing) to compute multivariable-adjusted sub-distribution HRs and corresponding 95\% CIs (Model 2) for hip fracture with the nine cross-classified strata of dietary calcium intake and mMED as exposure. In this analysis missing values on any of the eight components of the mMED was treated as 0 . This analysis comprised of 63,666 subjects and included 4386 hip fractures. Then, the same complete case data was subsequently used in the competing risk analysis, by the method of Fine and Gray.

\section{Results}

\subsection{Baseline characteristics}

At baseline, the participants were, on average, 61 years old. Baseline characteristics within the nine combined strata between calcium intake and mMED adherence are displayed in Table 1 . The average daily dietary calcium intake for women was $1043 \mathrm{mg}$ and for men $1467 \mathrm{mg}$. In total, $12 \%$ of the participants had a daily calcium intake below $800 \mathrm{mg}$, and 51\% had an intake higher than $1200 \mathrm{mg}$. Moreover, $44 \%$ of the participants reported dietary habits consistent with high adherence to MMED and $8 \%$ with low adherence. Between the different strata of calcium intake and mMED adherence, there were no large differences in baseline characteristics than those expected. For example, there were differences in the intakes of fruit, vegetables, and dairy, which are related to the exposures.

\subsection{Separate analyses of dietary calcium and $M M E D$}

During up to 20 years of follow-up, including 1,367,260 personyears at risk, 5938 participants (3613 women and 2325 men) experienced a hip fracture. Women and men with a daily intake of calcium below $800 \mathrm{mg}$ had higher multivariable adjusted Hazard Ratios (HR) of hip fractures in a dose-dependent pattern (Fig. 1). Intakes above $800 \mathrm{mg}$ of calcium were associated with a lower rate of hip fracture in a non-linear pattern, with an inflection point at higher calcium intake levels in men compared with women. There was an inverse, almost linear, association between adherence to mMED and incident hip fracture (Fig. 2) in both women (HR $=0.87$, 


\begin{tabular}{|c|c|c|c|c|c|c|c|c|c|}
\hline & $\begin{array}{l}\text { Calc1 } \\
\text { mMED1 }\end{array}$ & $\begin{array}{l}\text { Calc1 } \\
\text { mMED2 }\end{array}$ & $\begin{array}{l}\text { Calc1 } \\
\text { mMED3 }\end{array}$ & $\begin{array}{l}\text { Calc2 } \\
\text { mMED1 }\end{array}$ & $\begin{array}{l}\text { Calc2 } \\
\text { mMED2 }\end{array}$ & $\begin{array}{l}\text { Calc2 } \\
\text { mMED3 }\end{array}$ & $\begin{array}{l}\text { Calc3 } \\
\text { mMED1 }\end{array}$ & $\begin{array}{l}\text { Calc3 } \\
\text { mMED2 }\end{array}$ & $\begin{array}{l}\text { Calc3 } \\
\text { mMED3 }\end{array}$ \\
\hline Number of participants & 1538 & 5121 & 2943 & 1932 & 14,445 & 14,59 & 2973 & 19,679 & 18,871 \\
\hline Number of men, $n(\%)$ & $592(38.5 \%)$ & $1441(28.1 \%)$ & $383(13.0 \%)$ & $895(46.3 \%)$ & $5858(40.6 \%)$ & $4182(28.7 \%)$ & $2249(75.6 \%)$ & $\begin{array}{l}15,442 \\
(78.5 \%)\end{array}$ & $\begin{array}{l}14,297 \\
(75.8 \%)\end{array}$ \\
\hline Age (years), mean (SD) & $65(10)$ & $62(9.5)$ & $59(8.6)$ & $65(10)$ & $63(9.7)$ & $60(8.8)$ & $64(10)$ & $62(9.8)$ & $60(9.2)$ \\
\hline Height $(\mathrm{cm})$, mean $(\mathrm{SD})$ & $168(8.5)$ & $168(8.2)$ & $167(7.2)$ & $169(8.7)$ & $169(8.8)$ & $169(8.2)$ & $173(8.7)$ & $174(8.3)$ & $175(8.4)$ \\
\hline $\begin{array}{l}\text { Body Mass Index }(\mathrm{kg} / \\
\left.\mathrm{m}^{2}\right) \text {, mean }(\mathrm{SD})\end{array}$ & $25(4.1)$ & $25(3.9)$ & $25(3.7)$ & $26(4.1)$ & $25(3.8)$ & $25(3.5)$ & $26(4)$ & $26(3.6)$ & $26(3.4)$ \\
\hline Living alone, n (\%) & $468(33.1 \%)$ & $1065(23.0 \%)$ & $423(16.5 \%)$ & $580(32.6 \%)$ & $3012(22.6 \%)$ & $2260(17.2 \%)$ & $953(33.7 \%)$ & 4014 (21.1\%) & $2757(15.2 \%)$ \\
\hline \multicolumn{10}{|l|}{$\begin{array}{l}\text { Number of } \\
\quad \text { comorbidities, } n(\%)\end{array}$} \\
\hline 0 & $1261(82.0 \%)$ & $4446(86.8 \%)$ & $2695(91.6 \%)$ & $1602(82.9 \%)$ & $\begin{array}{l}12,594 \\
(87.2 \%)\end{array}$ & $\begin{array}{l}13,190 \\
(90.4 \%)\end{array}$ & $2355(79.2 \%)$ & $\begin{array}{l}16,793 \\
(85.3 \%)\end{array}$ & $\begin{array}{l}16,656 \\
(88.3 \%)\end{array}$ \\
\hline 1 & $243(15.8 \%)$ & $625(12.2 \%)$ & $230(7.8 \%)$ & $290(15.0 \%)$ & $1686(11.7 \%)$ & $1329(9.1 \%)$ & $539(18.1 \%)$ & $2604(13.2 \%)$ & $2037(10.8 \%)$ \\
\hline 2 or more & $34(2.2 \%)$ & $50(1.0 \%)$ & $18(0.6 \%)$ & $40(2.1 \%)$ & $165(1.1 \%)$ & $71(0.5 \%)$ & 79 (2.7\%) & $282(1.4 \%)$ & $178(0.9 \%)$ \\
\hline $\begin{array}{l}\text { Any calcium } \\
\text { supplement, } \\
\text { including } \\
\text { multivitamins, n (\%) }\end{array}$ & $196(12.7 \%)$ & $1017(19.9 \%)$ & $836(28.4 \%)$ & $245(12.7 \%)$ & $2624(18.2 \%)$ & 3946 (27.0\%) & $313(10.5 \%)$ & 2836 (14.4\%) & 3795 (20.1\%) \\
\hline $\begin{array}{l}\text { Calcium supplement, } \mathrm{n} \\
(\%)\end{array}$ & $59(3.8 \%)$ & $311(6.1 \%)$ & $246(8.4 \%)$ & $56(2.9 \%)$ & $529(3.7 \%)$ & $877(6.0 \%)$ & $66(2.2 \%)$ & $497(2.5 \%)$ & $685(3.6 \%)$ \\
\hline $\begin{array}{l}\text { Vitamin D supplement, } \\
\mathrm{n}(\%)\end{array}$ & $186(12.1 \%)$ & $928(18.1 \%)$ & $767(26.1 \%)$ & $256(13.3 \%)$ & $2575(17.8 \%)$ & $3725(25.5 \%)$ & $354(11.9 \%)$ & $3109(15.8 \%)$ & $3978(21.1 \%)$ \\
\hline Cortisone use & $164(10.7 \%)$ & $611(11.9 \%)$ & $390(13.3 \%)$ & $220(11.4 \%)$ & $1605(11.1 \%)$ & $1686(11.6 \%)$ & $271(9.1 \%)$ & $1584(8.0 \%)$ & $1550(8.2 \%)$ \\
\hline \multicolumn{10}{|l|}{ Smoking status, n (\%) } \\
\hline Current & $466(31.4 \%)$ & $1336(26.6 \%)$ & $668(23.2 \%)$ & $551(29.2 \%)$ & $3355(23.6 \%)$ & 3007 (20.9\%) & $997(34.8 \%)$ & $5092(26.3 \%)$ & $3994(21.4 \%)$ \\
\hline Former & $346(23.3 \%)$ & $1331(26.5 \%)$ & $880(30.5 \%)$ & 449 (23.8\%) & $3878(27.3 \%)$ & 4476 (31.1\%) & $754(26.3 \%)$ & $6361(32.9 \%)$ & 7221 (38.7\%) \\
\hline Never & $673(45.3 \%)$ & $2360(46.9 \%)$ & $1333(46.3 \%)$ & $889(47.1 \%)$ & $6990(49.1 \%)$ & $6924(48.1 \%)$ & $1114(38.9 \%)$ & $7903(40.8 \%)$ & 7451 (39.9\%) \\
\hline \multicolumn{10}{|l|}{ Hours of exercise, $n(\%)$} \\
\hline$<1 \mathrm{~h} /$ week & $432(35.5 \%)$ & $1118(24.9 \%)$ & $471(17.5 \%)$ & $512(32.3 \%)$ & $3011(23.3 \%)$ & $2070(15.4 \%)$ & $752(31.8 \%)$ & $4163(23.9 \%)$ & $2824(16.4 \%)$ \\
\hline $1 \mathrm{~h} /$ week & 231 (19.0\%) & $1035(23.1 \%)$ & $645(24.0 \%)$ & 307 (19.4\%) & $2808(21.7 \%)$ & $3072(22.9 \%)$ & 447 (18.9\%) & 3460 (19.8\%) & 3435 (19.9\%) \\
\hline $2-3 \mathrm{~h} /$ week & $314(25.8 \%)$ & $1369(30.5 \%)$ & $913(34.0 \%)$ & $426(26.9 \%)$ & $4022(31.2 \%)$ & 4814 (35.9\%) & $631(26.7 \%)$ & $5240(30.1 \%)$ & $6029(34.9 \%)$ \\
\hline $4-5 \mathrm{~h} /$ week & $113(9.3 \%)$ & $456(10.2 \%)$ & $332(12.4 \%)$ & $152(9.6 \%)$ & $1468(11.4 \%)$ & $1746(13.0 \%)$ & $241(10.2 \%)$ & $2145(12.3 \%)$ & $2402(13.9 \%)$ \\
\hline$\geq 5 \mathrm{~h} /$ week & $126(10.4 \%)$ & $510(11.4 \%)$ & $325(12.1 \%)$ & $186(11.7 \%)$ & $1602(12.4 \%)$ & $1712(12.8 \%)$ & $296(12.5 \%)$ & $2423(13.9 \%)$ & $2573(14.9 \%)$ \\
\hline \multicolumn{10}{|l|}{ Hours of walking, $n(\%)$} \\
\hline Almost never & $285(22.4 \%)$ & $736(15.9 \%)$ & $255(9.3 \%)$ & $378(22.7 \%)$ & $1807(13.6 \%)$ & $1084(7.9 \%)$ & $510(20.5 \%)$ & $2625(14.7 \%)$ & $1655(9.5 \%)$ \\
\hline$<20 \mathrm{~min} /$ day & $265(20.8 \%)$ & $991(21.5 \%)$ & $522(19.1 \%)$ & 369 (22.1\%) & 2896 (21.9\%) & $2701(19.8 \%)$ & $545(21.9 \%)$ & $4165(23.4 \%)$ & 3917 (22.5\%) \\
\hline $20-40 \mathrm{~min} /$ day & $336(26.4 \%)$ & $1433(31.0 \%)$ & $1020(37.3 \%)$ & $432(25.9 \%)$ & 4076 (30.8\%) & 4866 (35.7\%) & $672(27.1 \%)$ & 5077 (28.5\%) & $5684(32.6 \%)$ \\
\hline $40-60 \mathrm{~min} /$ day & $188(14.8 \%)$ & $683(14.8 \%)$ & $484(17.7 \%)$ & $211(12.7 \%)$ & $2180(16.4 \%)$ & $2653(19.4 \%)$ & $331(13.3 \%)$ & $2741(15.4 \%)$ & $3084(17.7 \%)$ \\
\hline $1-1.5 \mathrm{~h} /$ day & $107(8.4 \%)$ & $434(9.4 \%)$ & $261(9.5 \%)$ & 139 (8.3\%) & $1264(9.5 \%)$ & $1335(9.8 \%)$ & $183(7.4 \%)$ & $1705(9.6 \%)$ & $1710(9.8 \%)$ \\
\hline$>1.5 \mathrm{~h} /$ day & $92(7.2 \%)$ & 341 (7.4\%) & $195(7.1 \%)$ & $138(8.3 \%)$ & $1030(7.8 \%)$ & $1008(7.4 \%)$ & $242(9.7 \%)$ & $1505(8.4 \%)$ & $1392(8.0 \%)$ \\
\hline \multicolumn{10}{|l|}{ Educational level, n (\%) } \\
\hline$<10$ years & $1325(87.2 \%)$ & $3943(77.5 \%)$ & $1865(63.5 \%)$ & $1615(84.2 \%)$ & $\begin{array}{l}11,146 \\
(77.5 \%)\end{array}$ & 9115 (62.6\%) & 2514 (85.9\%) & $\begin{array}{l}15,081 \\
(77.2 \%)\end{array}$ & $\begin{array}{l}11,879 \\
(63.2 \%)\end{array}$ \\
\hline $10-12$ years & 91 (6.0\%) & 453 (8.9\%) & 338 (11.5\%) & 137 (7.1\%) & $1400(9.7 \%)$ & $1715(11.8 \%)$ & 206 (7.0\%) & 2053 (10.5\%) & $2643(14.1 \%)$ \\
\hline$>12$ years & $104(6.8 \%)$ & 690 (13.6\%) & $733(25.0 \%)$ & $166(8.7 \%)$ & $1828(12.7 \%)$ & $3727(25.6 \%)$ & $208(7.1 \%)$ & 2411 (12.3\%) & $4270(22.7 \%)$ \\
\hline $\begin{array}{l}\text { Energy intake (kcal), } \\
\text { median (IOR) }\end{array}$ & $\begin{array}{l}1513(1114, \\
2106)\end{array}$ & $\begin{array}{l}1769(1405, \\
2297)\end{array}$ & $1883(1565$ & $1539(1138$ & $1875(1472$ & $1969(1627$ & $1747(1245$ & $2285(1762$ & 2505 \\
\hline $\begin{array}{l}\text { Alcohol (gram), median } \\
\text { (IQR) }\end{array}$ & $0.6(0,3.7)$ & $2.9(0.52,8.9)$ & $6.3(3.2,10)$ & $0.6(0,3.6)$ & $\begin{array}{l}2452) \\
2.5(0.45,9)\end{array}$ & $\begin{array}{l}24 / 0) \\
6.1(2.9,11)\end{array}$ & $\begin{array}{l}2363) \\
0.7(0,3.4)\end{array}$ & $\begin{array}{l}2900) \\
3.8(0.76,11)\end{array}$ & $\begin{array}{l}(2010,3055) \\
7.7(4,13)\end{array}$ \\
\hline \multicolumn{10}{|c|}{ Nutrient intakes per day, residual adjusted, median (IQR) } \\
\hline Calcium (mg) & $\begin{array}{l}621(495, \\
717)\end{array}$ & $\begin{array}{l}686(594, \\
750)\end{array}$ & $\begin{array}{l}721(651, \\
766)\end{array}$ & $\begin{array}{l}1002(905, \\
1097)\end{array}$ & $\begin{array}{l}1008(912, \\
1103)\end{array}$ & $\begin{array}{l}1017(920, \\
1108)\end{array}$ & $\begin{array}{l}1630(1385, \\
1987)\end{array}$ & $\begin{array}{l}1536(1347, \\
1811)\end{array}$ & $\begin{array}{l}1499(1335, \\
1745)\end{array}$ \\
\hline Retinol (gram) & $\begin{array}{l}0.66(0.45, \\
1.3)\end{array}$ & $0.7(0.48,1.3)$ & $\begin{array}{l}0.61(0.44, \\
1.1)\end{array}$ & $\begin{array}{l}0.75(0.57, \\
1.3)\end{array}$ & $\begin{array}{l}0.79(0.58, \\
1.3)\end{array}$ & $\begin{array}{l}0.71(0.53, \\
1.2)\end{array}$ & $\begin{array}{l}0.96(0.76 \\
1.4)\end{array}$ & $1.0(0.76,1.5)$ & $\begin{array}{l}0.94(0.72 \\
1.4)\end{array}$ \\
\hline Vitamin D $(\mu \mathrm{g})$ & $4.5(3.4,6.1)$ & $4.6(3.6,5.8)$ & $4.3(3.5,5.3)$ & $4.7(3.6,6.1)$ & $4.9(3.9,6.2)$ & $4.6(3.8,5.8)$ & $5.5(4.1,7.3)$ & $6(4.6,7.5)$ & $6(4.8,7.4)$ \\
\hline
\end{tabular}




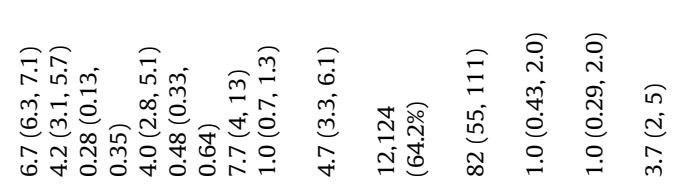

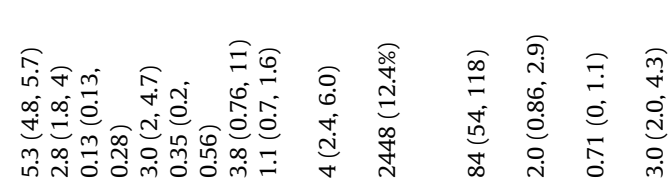

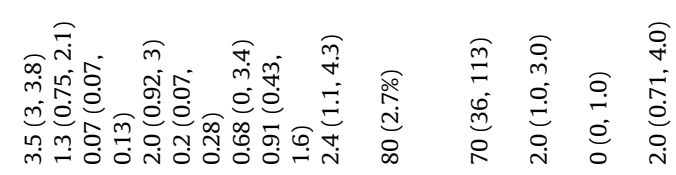

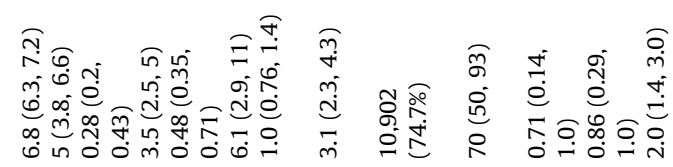

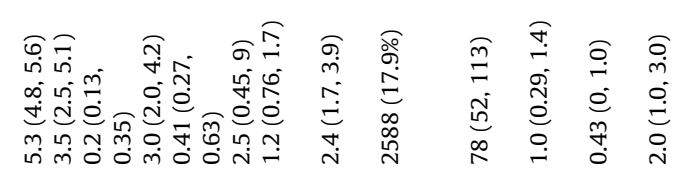

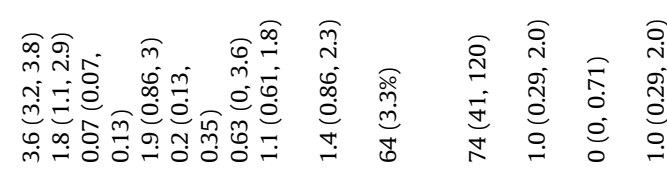

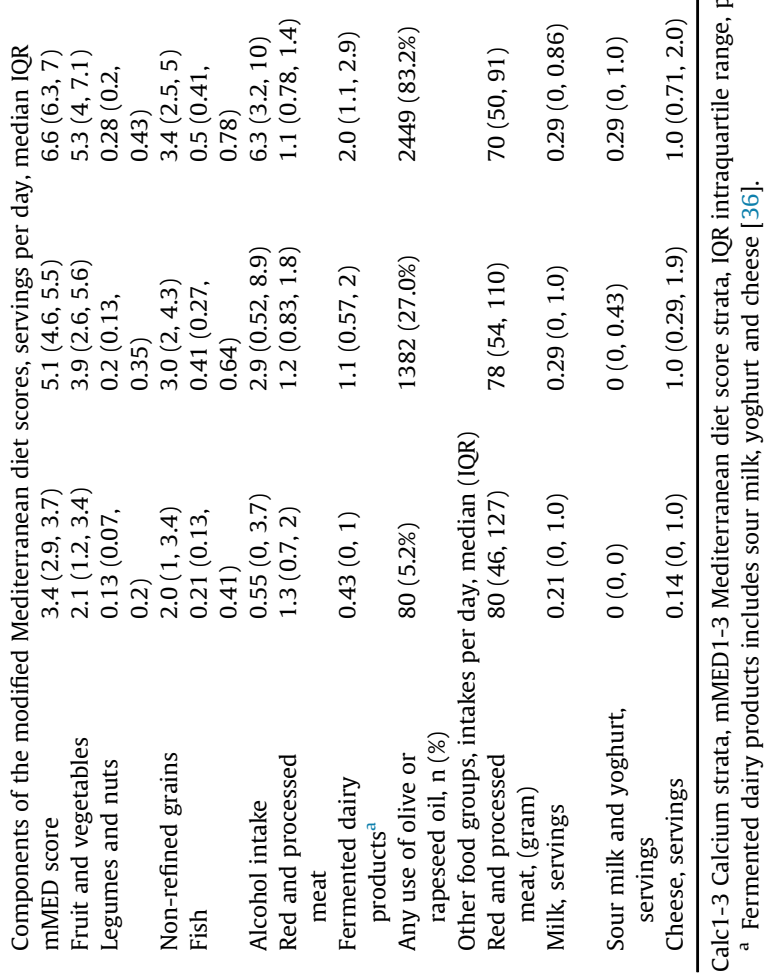

95\% Confidence Interval ( $\mathrm{CI}$ ) 0.84; 0.91 per higher mMED score) and men $(\mathrm{HR}=0.93,95 \% \mathrm{CI} 0.88 ; 0.98$ per higher mMED score $)$.

\subsection{Combined strata of dietary calcium and $\mathrm{MMED}$}

The results from the two multivariable models (Models 1 and 2 ) using the nine cross-classified strata of dietary calcium intake and mMED are depicted in Tables 2 and 3. The HRs of hip fracture were consistently lower with a higher adherence to mMED at all calcium intake levels. The HRs and 95\% CIs were attenuated in Model 2 compared to Model 1. The multivariable adjusted (Model 2) associations for hip fracture across the combined strata of dietary calcium intake and mMED are also illustrated with the heatmaps in Fig. 3. The analysis revealed a similar HR in the stratum of medium calcium intake (800-1200 mg/day) and high mMED as for the reference stratum, in all participants (Table 2 and Fig. 3, panel A) as well as among women (Table 3 and Fig. 3, panel B) and men (Table 3 and Fig. 3, panel C). Otherwise, higher HR of hip fracture were found in all other strata in all participants, as well as in women and men. In all participants, we found no dose-response trend for calcium intake within categories of mMED. Among men, successively lower mMED revealed higher rates of hip fracture, except for in the low calcium category. The highest rate of hip fractures, displaying the highest HRs was among those with low adherence to mMED, irrespective of a low or high dietary calcium intake in women. In men, the highest HR of hip fracture was found for participants in the low calcium/high mMED category (Fig. 3, panel C).

\subsection{Complete case analysis and competing risks}

The results from the multivariable adjusted complete case Cox regression analysis using the nine cross-classified strata of dietary calcium intake and MMED in men and women combined are shown in Table 4. The HRs of hip fracture were similar to the main analysis as shown in Table 2. The results from the subdistribution proportional hazards model using the complete case dataset, are shown in a heatmap in the Supplemental Material 3. These results suggest no major effect of competing risk.

\subsection{Additional analyses}

Additional sensitivity and exploratory analyses were performed. More information on these analyses as well as their results are described in the Supplemental Material 4. The results from the sensitivity analyses revealed similar results after additional adjustment for milk, fermented milk (sour milk and yoghurt) and cheese, compared to the primary analyses. The results from the exploratory analysis did not change the interpretation of the study's results.

\section{Discussion}

The results from this large longitudinal cohort study of middleaged and older adults indicated that there was a non-linear association between dietary calcium intake and hip fracture. Adherence to a Mediterranean-style diet was associated with decreased hip fracture rates in a dose-response pattern. In combination, dietary calcium in the context of an overall healthy diet is important for the prevention of hip fractures, in both women and men. Individuals with moderate (800-1200 mg) or high ( $>1200 \mathrm{mg} /$ day) dietary calcium intake combined with high adherence to the mMED had the lowest rates of hip fracture. However, a high calcium intake did not counteract the higher hip 


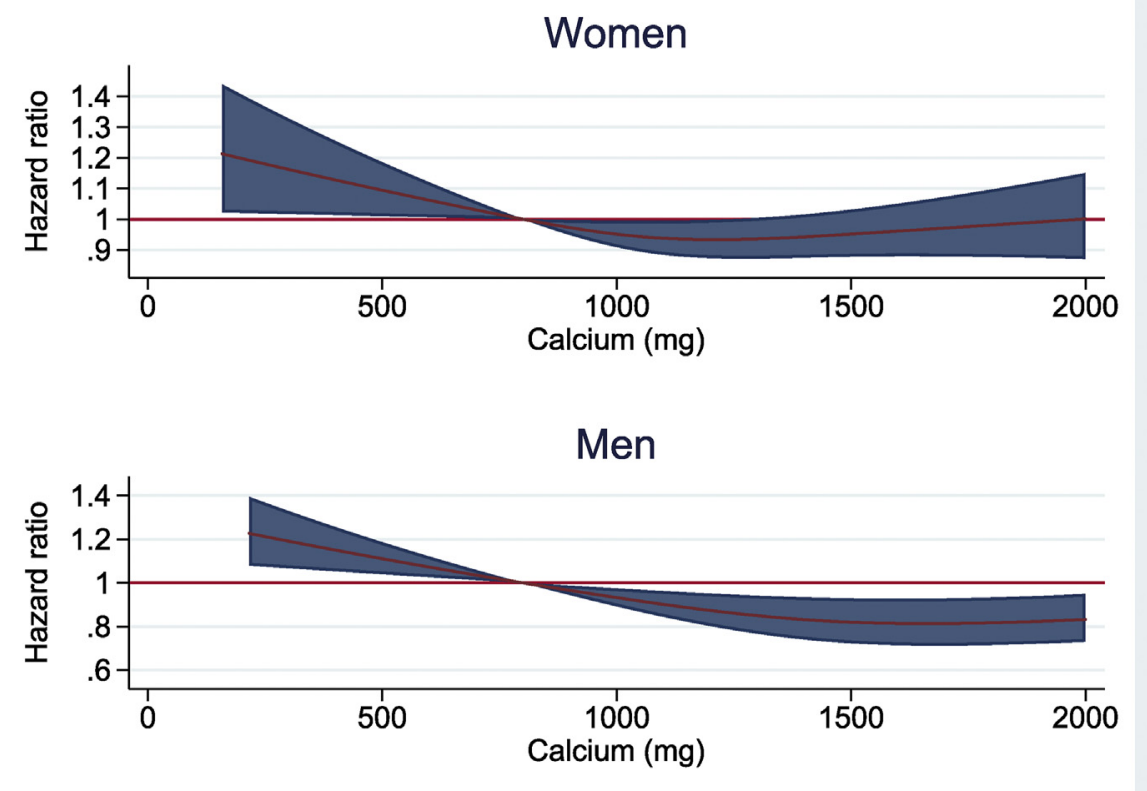

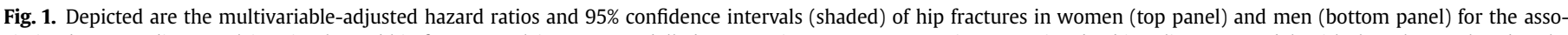

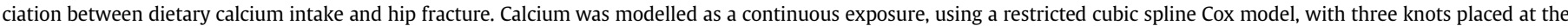

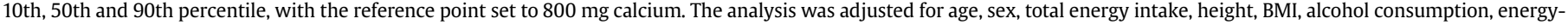

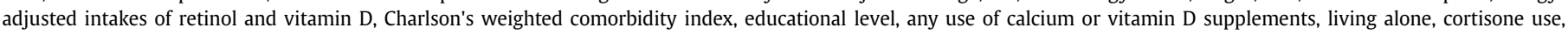
physical activity, walking/cycling and smoking status.

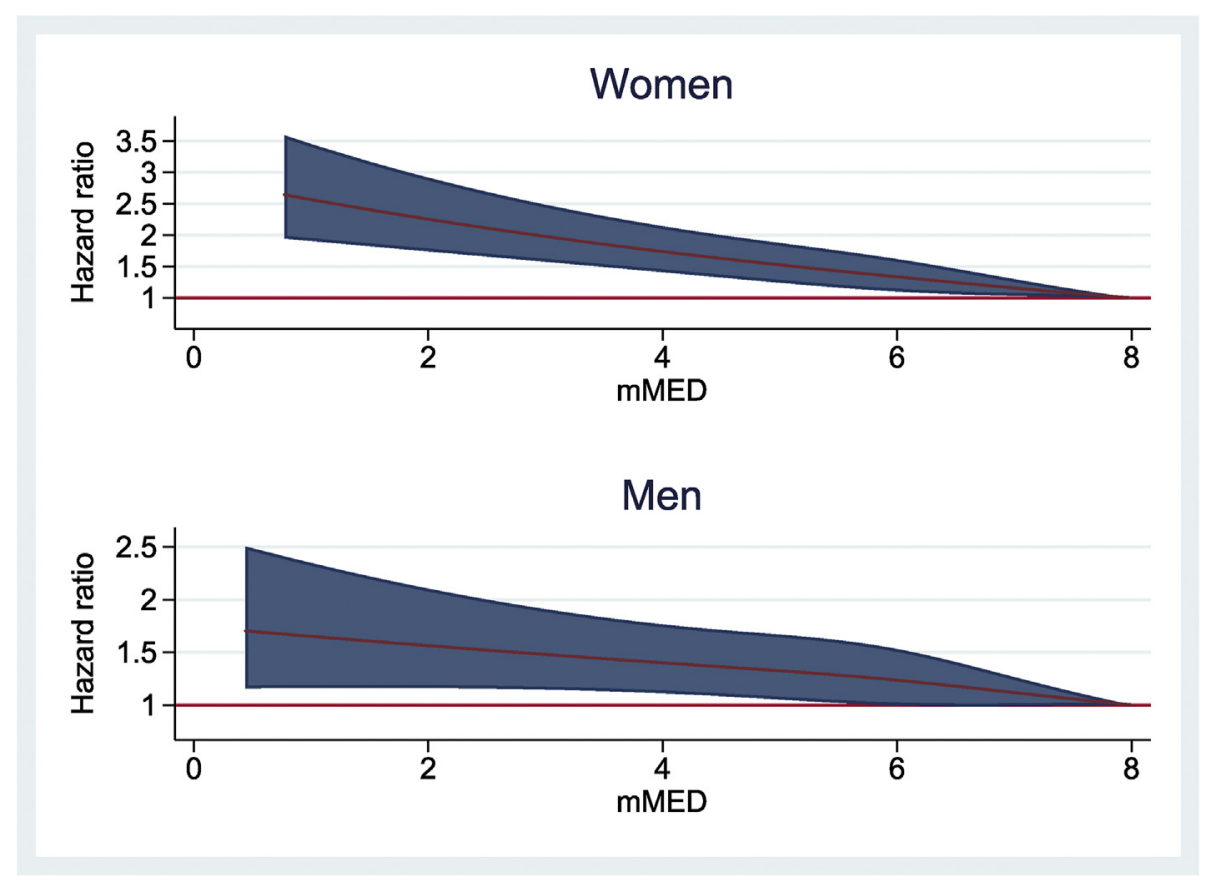

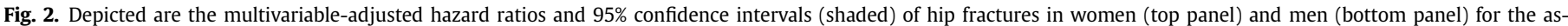

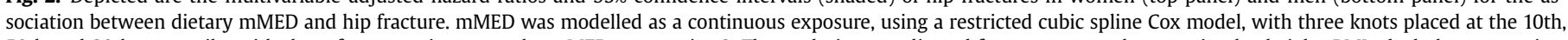

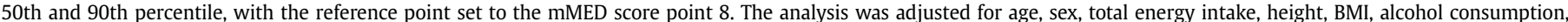

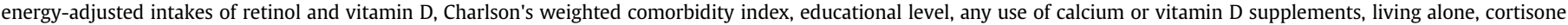
use, physical activity, walking/cycling and smoking status.

fracture risk associated with a low adherence to mMED. These results suggest that for optimal prevention of future hip fractures in this study population, a normal to high calcium intake should be combined with adherence to mMED.
Bone is constantly remodelled, both in order to replace old and damaged bone, and to maintain long-term calcium homeostasis. If calcium is cumulatively depleted from the skeleton over several years, this leads to osteoporosis and an increased risk of fracture. 
Table 2

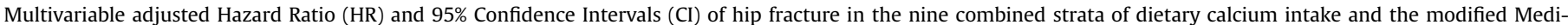
terranean diet score $(\mathrm{mMED})$ in all participants $(\mathrm{n}=\mathbf{8 2}, 092$ and 5,938 hip fractures).

\begin{tabular}{|c|c|c|c|c|c|c|c|c|c|}
\hline & Calc1 mMED1 & Calc1 mMED2 & Calc1 mMED3 & Calc2 mMED1 & Calc2 mMED2 & Calc2 mMED3 & Calc3 mMED1 & Calc3 mMED2 & Calc3 mMED3 \\
\hline $\begin{array}{l}\text { Model } 1 \\
\qquad \text { HR (95\% CI) }\end{array}$ & $\begin{array}{l}1.82 \\
(1.51,2.19)\end{array}$ & $\begin{array}{l}1.39 \\
(1.22,1.57)\end{array}$ & $\begin{array}{l}1.29 \\
(1.07,1.55)\end{array}$ & $\begin{array}{l}1.61 \\
(1.38,1.88)\end{array}$ & $\begin{array}{l}1.27 \\
(1.16,1.40)\end{array}$ & $\begin{array}{l}1.05 \\
(0.95,1.16)\end{array}$ & $\begin{array}{l}1.78 \\
(1.53,2.08)\end{array}$ & $\begin{array}{l}1.31 \\
(1.19,1.43)\end{array}$ & Reference, 1.00 \\
\hline $\begin{array}{l}\text { Model } 2 \\
\quad \text { HR (95\% CI) }\end{array}$ & $\begin{array}{l}1.54 \\
(1.28,1.85)\end{array}$ & $\begin{array}{l}1.27 \\
(1.10,1.47)\end{array}$ & $\begin{array}{l}1.28 \\
(1.06,1.54)\end{array}$ & $\begin{array}{l}1.40 \\
(1.19,1.65)\end{array}$ & $\begin{array}{l}1.18 \\
(1.06,1.31)\end{array}$ & $\begin{array}{l}1.06 \\
(0.95,1.17)\end{array}$ & $\begin{array}{l}1.50 \\
(1.26,1.77)\end{array}$ & $\begin{array}{l}1.18 \\
(1.08,1.30)\end{array}$ & Reference, 1.00 \\
\hline
\end{tabular}

Calc1-3 Calcium strata mMED1-3 Mediterranean diet score strata HR Hazard Ratio CI Confidence Interval py person-years.

Hazard ratios $(95 \% \mathrm{CI})$ were determined in Cox Proportional hazard analysis using time-updated variables.

Model 1 was adjusted for sex, age (splines with three knots).

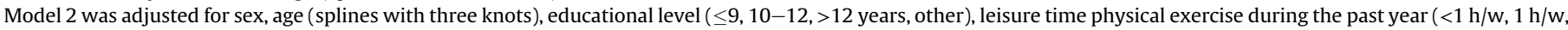

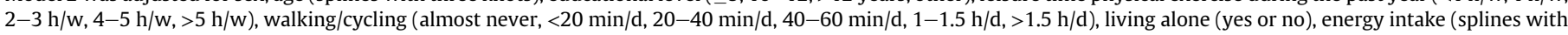

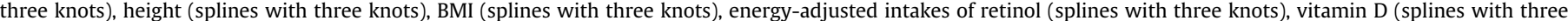

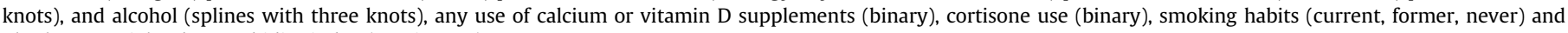
Charlson's weighted comorbidity index (continuous).

Table 3

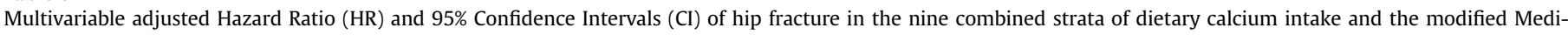
terranean diet score (mMED) in women and men.

\begin{tabular}{|c|c|c|c|c|c|c|c|c|c|}
\hline & $\begin{array}{l}\text { Calc1 } \\
\text { mMED1 }\end{array}$ & $\begin{array}{l}\text { Calc1 } \\
\text { mMED2 }\end{array}$ & $\begin{array}{l}\text { Calc1 } \\
\text { mMED3 }\end{array}$ & $\begin{array}{l}\text { Calc2 } \\
\text { mMED1 }\end{array}$ & $\begin{array}{l}\text { Calc2 } \\
\text { mMED2 }\end{array}$ & $\begin{array}{l}\text { Calc2 } \\
\text { mMED3 }\end{array}$ & $\begin{array}{l}\text { Calc3 } \\
\text { mMED1 }\end{array}$ & $\begin{array}{l}\text { Calc3 } \\
\text { mMED2 }\end{array}$ & $\begin{array}{l}\text { Calc3 } \\
\text { mMED3 }\end{array}$ \\
\hline \multicolumn{10}{|c|}{ Women $(\mathrm{n}=36,753, \mathrm{n}$ hip fractures $=3,613)$} \\
\hline $\begin{array}{l}\text { Model } 1 \\
\text { HR (95\% CI) }\end{array}$ & $\begin{array}{l}1.73 \\
(1.40,2.15)\end{array}$ & $\begin{array}{l}1.27 \\
(1.09,1.49)\end{array}$ & $\begin{array}{l}1.21 \\
(0.99,1.47)\end{array}$ & $\begin{array}{l}1.51 \\
(1.24,1.86)\end{array}$ & $\begin{array}{l}1.23 \\
(1.08,1.39)\end{array}$ & $\begin{array}{l}1.00 \\
(0.88,1.13)\end{array}$ & $\begin{array}{l}1.83 \\
(1.47,2.29)\end{array}$ & $\begin{array}{l}1.24 \\
(1.08,1.43)\end{array}$ & Reference, 1.00 \\
\hline Model 2 & 1.56 & 1.21 & 1.21 & 1.40 & 1.16 & 1.01 & 1.64 & 1.16 & Reference, 1.00 \\
\hline HR (95\% CI) & $(1.25,1.95)$ & $(1.02,1.43)$ & $(0.98,1.49)$ & $(1.14,1.72)$ & $(1.01,1.33)$ & $(0.89,1.15)$ & $(1.27,2.11)$ & $(1.00,1.34)$ & \\
\hline \multicolumn{10}{|c|}{ Men $(n=45,339, n$ hip fractures $=2325)$} \\
\hline $\begin{array}{l}\text { Model } 1 \\
\text { HR }(95 \% \text { CI })\end{array}$ & $\begin{array}{l}1.94 \\
(1.36,2.77)\end{array}$ & $\begin{array}{l}1.75 \\
(1.37,2.23)\end{array}$ & $\begin{array}{l}1.66 \\
(1.00,2.73)\end{array}$ & $\begin{array}{l}1.71 \\
(1.33,2.19)\end{array}$ & $\begin{array}{l}1.29 \\
(1.12,1.50)\end{array}$ & $\begin{array}{l}1.11 \\
(0.92,1.34)\end{array}$ & $\begin{array}{l}1.75 \\
(1.43,2.14)\end{array}$ & $\begin{array}{l}1.35 \\
(1.21,1.52)\end{array}$ & Reference, 1.00 \\
\hline $\begin{array}{l}\text { Model } 2 \\
\text { HR }(95 \% \text { CI })\end{array}$ & $\begin{array}{l}1.40 \\
(0.95,2.06)\end{array}$ & $\begin{array}{l}1.50 \\
(1.16,1.92)\end{array}$ & $\begin{array}{l}1.57 \\
(0.94,2.60)\end{array}$ & $\begin{array}{l}1.33 \\
(1.00,1.77)\end{array}$ & $\begin{array}{l}1.14 \\
(0.96,1.34)\end{array}$ & $\begin{array}{l}1.11 \\
(0.92,1.33)\end{array}$ & $\begin{array}{l}1.27 \\
(1.02,1.58)\end{array}$ & $\begin{array}{l}1.16 \\
(1.02,1.32)\end{array}$ & Reference, 1.00 \\
\hline
\end{tabular}

Calc1-3 Calcium strata mMED1-3 Mediterranean diet score strata HR Hazard Ratio CI Confidence Interval py person-years.

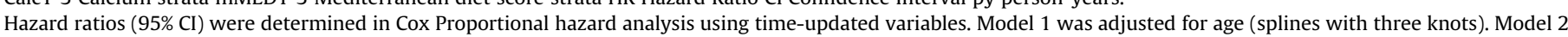

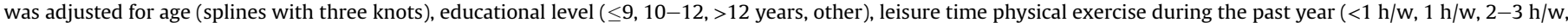

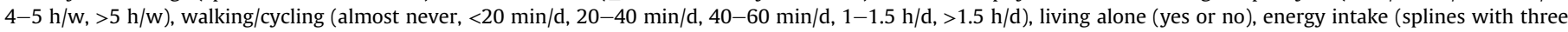

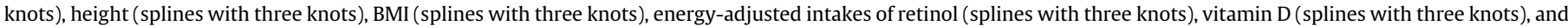

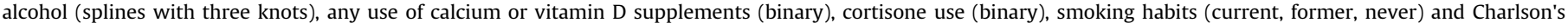
weighted comorbidity index (continuous).
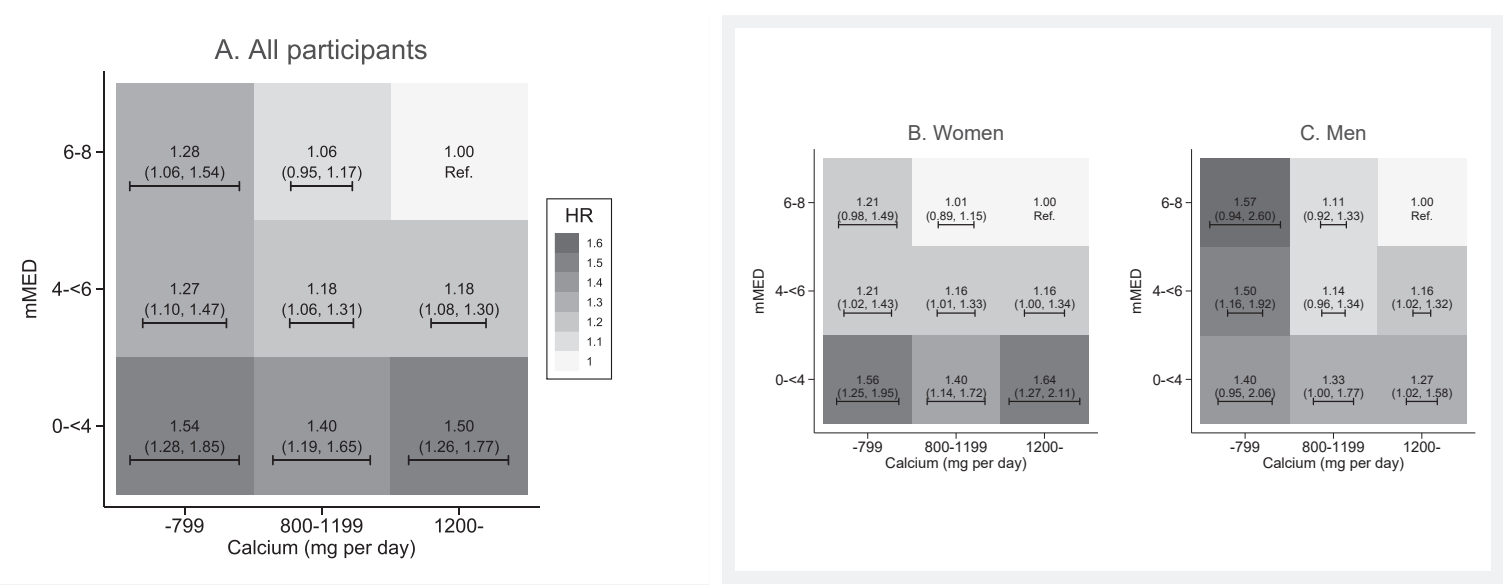

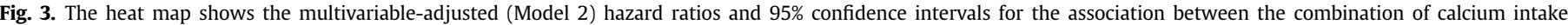

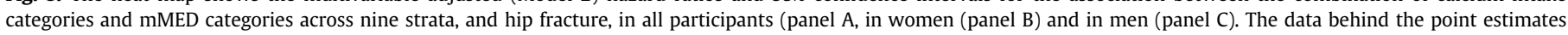

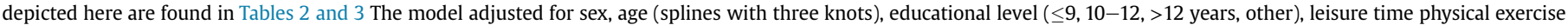

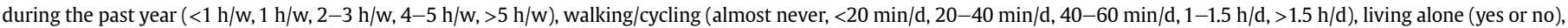

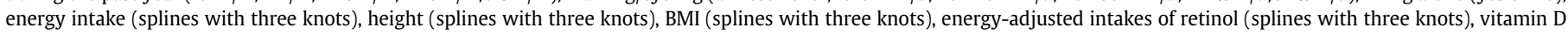

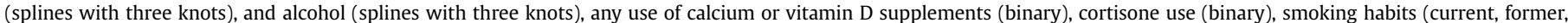
never) and Charlson's weighted comorbidity index (continuous).

This may cause a conflict in older people when vitamin D production, and thereby calcium absorption, decreases. Secondary hyperparathyroidism may be the consequence of a lowered calcium absorption in order to maintain adequate serum calcium levels, thus further augmenting bone resorption [39]. Bone loss is however not only a consequence of impaired calcium homeostasis. During 
Table 4

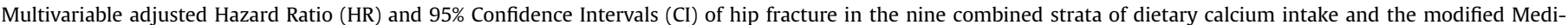
terranean diet score (mMED) in the complete case dataset of all participants $(n=63,666)$.

\begin{tabular}{|c|c|c|c|c|c|c|c|c|c|}
\hline & $\begin{array}{l}\text { Calc1 } \\
\text { mMED1 }\end{array}$ & $\begin{array}{l}\text { Calc1 } \\
\text { mMED2 }\end{array}$ & $\begin{array}{l}\text { Calc1 } \\
\text { mMED3 }\end{array}$ & $\begin{array}{l}\text { Calc2 } \\
\text { mMED1 }\end{array}$ & $\begin{array}{l}\text { Calc2 } \\
\text { mMED2 }\end{array}$ & $\begin{array}{l}\text { Calc2 } \\
\text { mMED3 }\end{array}$ & $\begin{array}{l}\text { Calc3 } \\
\text { mMED1 }\end{array}$ & $\begin{array}{l}\text { Calc3 } \\
\text { mMED2 }\end{array}$ & $\begin{array}{l}\text { Calc3 } \\
\text { mMED3 }\end{array}$ \\
\hline Number of hip fractures & 107 & 330 & 158 & 150 & 881 & 769 & 175 & 1027 & 789 \\
\hline Person-years at risk & 13,407 & 61,034 & 40,254 & 16,964 & 178,298 & 237,023 & 24,093 & 250,928 & 349,034 \\
\hline Rate per 1000 py (95\% CI) & $7.3(6.0,8.8)$ & $5.2(4.7,5.8)$ & $4.0(3.4,4.6)$ & $7.6(6.5,8.9)$ & $4.8(4.5,5.1)$ & $3.8(3.5,4.1)$ & $6.3(5.5,7.3)$ & $4.1(3.9,4.4)$ & $2.9(2.7,3.1)$ \\
\hline $\operatorname{HR}(95 \% \mathrm{CI})$ & $\begin{array}{l}1.49 \\
(1.21,1.84)\end{array}$ & $\begin{array}{l}1.21 \\
(1.06,1.39)\end{array}$ & $\begin{array}{l}1.15 \\
(0.97,1.38)\end{array}$ & $\begin{array}{l}1.50 \\
(1.25,1.81)\end{array}$ & $\begin{array}{l}1.09 \\
(0.99,1.21)\end{array}$ & $\begin{array}{l}1.06 \\
(0.96,1.18)\end{array}$ & $\begin{array}{l}1.43 \\
(1.20,1.71)\end{array}$ & $\begin{array}{l}1.15 \\
(1.04,1.27)\end{array}$ & Reference, 1.00 \\
\hline
\end{tabular}

Calc1-3 Calcium strata mMED1-3 Mediterranean diet score strata HR Hazard Ratio CI Confidence Interval py person-years.

Hazard ratios $(95 \% \mathrm{CI})$ were determined in Cox Proportional hazard analysis and setting missing mMED to 0 . The total number of hip fractures were 4386.

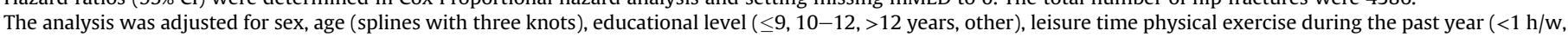

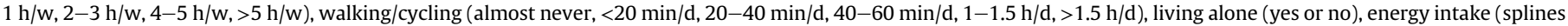

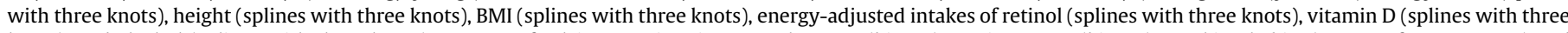

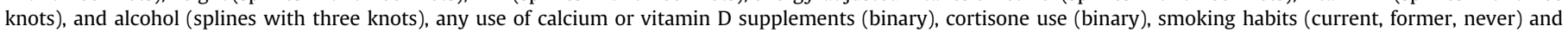
Charlson's weighted comorbidity index (continuous).

the past decade, it has also become evident that inflammation and sequential or concomitant oxidative stress with ageing is a fundamental pathogenic mechanism of age-related bone loss [40] and also possibly loss of muscle mass and sarcopenia [41,42]. Research suggests a progressive decrease in both bone and muscle mass by $1-2 \%$ per year after the age of 50 years [41]. By reducing the formation of free radicals and oxidative stress, the rate of bone loss and muscle wasting in the elderly can be reduced [40,41]. Other nutrients, apart from vitamin $\mathrm{D}$, which are potentially needed for optimal calcium balance are therefore nutrients with antioxidant properties, for example, vitamins $\mathrm{C}$ and $\mathrm{E}$ and carotenoids, as well as vitamin $\mathrm{K}$, potassium, magnesium, phosphorous, protein and fats [43]. Trace elements such as selenium, iron, zinc, and copper may also impact bone metabolism [44]. In addition, the supportive muscles of the bone need a supply of nutrients to keep them maintained $[12,43]$. In other words, in order to preserve bone tissue and muscles, there are additional requirements for other nutrients than just calcium, likely provided by healthy or Mediterraneanstyle diets. This partly explains the results of this study, which are in accordance with the conclusion from a recent scoping review, stating that adherence to a healthy dietary pattern can improve fracture risk, as well as bone mineral status and decrease risk for osteoporosis [45].

The present study also confirmed the inverse association between MMED and hip fractures previously reported in the same cohorts but with a shorter follow-up [46]. The mMED used in the present study is based on the Mediterranean diet scale by Trichopoulou et al. [25] and adapted to fit Swedish food culture. However, it shares food groups, nutrients and bioactive components with the traditional Mediterranean diet. The Mediterranean diet is characterised by an abundance of plant foods, olive oil, less fish and dairy products as well as less meat and a moderate intake of alcohol, mostly wine [47]. Healthy diets, including a Mediterranean-style diet, are rich in nutrients, antioxidants and other bioactive components, which may counteract inflammatory and oxidative stress responses in the body, including bone tissue [48]. Although randomised studies are lacking, a recent cohort study nested within the PREvencion con DIeta MEDiterranea (PREDIMED) trial reported that participants with the highest intakes of extra-virgin olive oil (but not common oil) had lower risk of fractures. The suggested mechanism was the content of bioactive and antioxidant components, such as polyphenols [49].

Previously, we published a study presenting an inverse J-shaped association between calcium intake and fracture risk in the SMC, an association that was stronger with hip fractures than with any other fractures [18]. This pattern was less apparent in this later follow-up with baseline in 1997, instead of 1987. The major sources of calcium in the Swedish diet are dairy products and cheese [50]. Results from another study conducted using data from the same cohorts as the present study, indicated that milk consumption was associated with higher rate of hip fractures in women, while intakes of fermented milk (sour milk and yoghurt) and cheese were inversely associated with hip fracture [51]. The relative contribution of milk as a calcium source has diminished with time. We found that additional adjustment for cheese, fermented milk or milk (Supplemental Material 4) did not change our results to a large extent. Further, the present results expand our findings by the inclusion of men as well as the inclusion of the effect modification of mMED in the analysis. That we observed a higher risk of hip fractures at low calcium intake levels $(<800 \mathrm{mg})$ in all three adherence categories of mMED in both sexes in the present study, suggest that adequate intake of calcium as part of a general healthy diet is important for the prevention of hip fractures.

The present study has both strengths and weaknesses worth mentioning. The two population-based studies, included in the present analyses, include a large number of hip fractures and both men and women. Further strengths include the complete ascertainment of hip fractures by use of a nationwide patient register, with no loss to follow-up and the repeated assessment of diet and a large number of covariates. Self-reports of hip fracture in other settings, with ties to comorbidity and high mortality rates during especially the first year after the fracture event, may lead to a high risk of collider stratification and selection bias. We also considered the potential competing risk problem from mortality in the present study by the method of Fine and Gray [38] and the interpretation of the result from this analysis was similar to that of the primary analysis. This suggests a minor effect of competing risk. It should also be noted that subhazard ratios from the Fine and Gray analysis are not directly comparable with ordinary cause-specific HRs and are not recommended to be used for etiologic analysis [52]. Although we have included a number of important covariates in our models, there is a possibility of residual or unmeasured confounding. Although the assessment of diet was done twice, which is a strength, there is a possibility that diets may have changed between the investigation at 2009 and time for follow-up, which is a weakness. The collection of diet data is inherently prone to a number of limitations. However, the study questionnaires have the ability to rank participants, and the large study size will compensate for random misclassification [53]. According to our previous validation study, dietary calcium intake is somewhat exaggerated (about $50 \mathrm{mg} /$ day) by use of the baseline FFQ [24]. A few of our participants had a very low calcium intake and this fact impeded us from evaluating extremely low calcium intakes. Most of our participants are also vitamin $D$ replete, according to previous analysis 
with gold standard methods [54] and contemporary suggestions for serum 25-hydroxyvitamin D threshold for deficiency, i.e. below 25-30 nmol/L [55]. Only half of all eligible men accepted to participate in the baseline investigation, which may have biased the representativeness. However, according to a previous analysis [56], the study populations of both the women in SMC and the men in COSM accords with the underlying Swedish population in terms of age, educational level and BMI, thus making the cohorts fairly representative. Nonetheless, it is possible that the study results may not be applicable to other populations with a more mixed ethnic background as well as age groups.

In conclusion, the present study suggests that dietary calcium intake in the context of an overall healthy diet, here studied as the mMED, is important in the prevention of hip fractures in both women and men. The results suggest that calcium alone is not sufficient for the optimal prevention of hip fractures, while a general healthy diet must contain moderate amounts of calcium. Thus, adequate calcium intake in the context of a healthy diet may be emphasized in preventive strategies for hip fracture. The observational nature of this study cannot prove causality and the present results should be confirmed in future studies.

\section{Funding sources}

The study was supported by grants from the Swedish Research Council (grant no 2015-03257, 2017-00644 and 2017-06100. The funders of the study had no role in the study design, data collection, data analysis, data interpretation, writing of the report, or the decision to submit the article for publication. We acknowledge the national research infrastructure SIMPLER for provisioning of facilities and experimental support. We would also like to thank AnnaKarin Kolseth for her assistance. SIMPLER receives funding through the Swedish Research Council under the grant no 2017-00644. The computations were performed with resources provided by the Swedish National Infrastructure for Computing's support for sensitive data SNIC-SENS through the Uppsala Multidisciplinary Center for Advanced Computational Science (UPPMAX) under Project SIMP2019004. SNIC is financially supported by the Swedish Research Council.

\section{Authors' contributions}

KM designed the research; EWL, LB, SCL, AW and KM conducted the research; JH performed statistical analysis; EWL drafted the paper; LB, SCL, AW and KM participated in the interpretation of data and in finalising the paper; EWL had primary responsibility for final content. All authors read and approved the final manuscript.

\section{Conflicts of interest}

The authors declare no conflict of interest.

\section{Appendix A. Supplementary data}

Supplementary data to this article can be found online at https://doi.org/10.1016/j.clnu.2021.01.043.

\section{References}

[1] Cauley JA, Chalhoub D, Kassem AM, Fuleihan Gel H. Geographic and ethnic disparities in osteoporotic fractures. Nat Rev Endocrinol 2014;10:338-51.

[2] Sattui SE, Saag KG. Fracture mortality: associations with epidemiology and osteoporosis treatment. Nat Rev Endocrinol 2014;10:592.

[3] Veronese N, Maggi S. Epidemiology and social costs of hip fracture. Injury 2018;49:1458-60.

[4] Weaver CM. Nutrition and bone health. Oral Dis 2017;23:412-5.
[5] Weaver CM, Gordon CM, Janz KF, Kalkwarf HJ, Lappe JM, Lewis R, et al. The National Osteoporosis Foundation's position statement on peak bone mass development and lifestyle factors: a systematic review and implementation recommendations. Osteoporos Int 2016;27:1281-386. a journal established as result of cooperation between the European Foundation for Osteoporosis and the National Osteoporosis Foundation of the USA.

[6] Kanis JA, Passmore R. Calcium supplementation of the diet - I. BMJ 1989;298: 137-40.

[7] Kanis JA, Passmore R. Calcium supplementation of the diet - II. BMJ 1989;298: 205-8.

[8] Nordin BEC, Heaney RP. Calcium supplementation of the diet: justified by present evidence. BMJ 1990;300:1056-60.

[9] Bolland MJ, Leung W, Tai V, Bastin S, Gamble GD, Grey A, et al. Calcium intake and risk of fracture: systematic review. BMJ (Clin Res ed) 2015;351:h4580.

[10] Kahwati LC, Weber RP, Pan H, Gourlay M, LeBlanc E, Coker-Schwimmer M, et al. Vitamin D, calcium, or combined supplementation for the primary prevention of fractures in community-dwelling adults: evidence report and systematic review for the US preventive services task force. Jama 2018;319: $1600-12$.

[11] Reid IR, Bristow SM, Bolland MJ. Calcium supplements: benefits and risks. J Intern Med 2015;278:354-68.

[12] Cashman KD. Diet, nutrition, and bone health. J Nutr 2007;137. 2507S-12S.

[13] Prentice A. Diet, nutrition and the prevention of osteoporosis. Publ Health Nutr 2004; 7:227-43.

[14] Benetou V, Orfanos P, Pettersson-Kymmer U, Bergstrom U, Svensson O, Johansson I, et al. Mediterranean diet and incidence of hip fractures in a European cohort. Osteoporos Int 2013;24:1587-98. a journal established as result of cooperation between the European Foundation for Osteoporosis and the National Osteoporosis Foundation of the USA.

[15] Byberg L, Bellavia A, Larsson SC, Orsini N, Wolk A, Michaelsson K. Mediterranean diet and hip fracture in Swedish men and women. J Bone Miner Res 2016;31(12):2098-105. https://doi.org/10.1002/jbmr.2896. Epub 2016 Sep 8.PMID: 27345330.

[16] Haring B, Crandall CJ, Wu C, LeBlanc ES, Shikany JM, Carbone L, et al. Dietary patterns and fractures in postmenopausal women: results from the women's health initiative. JAMA Intern Med 2016;176:645-52.

[17] Langsetmo L, Hanley DA, Prior JC, Barr SI, Anastassiades T, Towheed T, et al. Dietary patterns and incident low-trauma fractures in postmenopausal women and men aged $>/=50$ y: a population-based cohort study. Am J Clin Nutr 2011;93:192-9.

[18] Warensjo E, Byberg L, Melhus H, Gedeborg R, Mallmin H, Wolk A, et al. Dietary calcium intake and risk of fracture and osteoporosis: prospective longitudinal cohort study. BMJ 2011;342:d1473.

[19] Byberg L, Bellavia A, Orsini N, Wolk A, Michaelsson K. Fruit and vegetable intake and risk of hip fracture: a cohort study of Swedish men and women. J Bone Miner Res 2015;30:976-84. the official journal of the American Society for Bone and Mineral Research.

[20] Benetou V, Orfanos P, Feskanich D, Michaelsson K, Pettersson-Kymmer U, Eriksson S, et al. Fruit and vegetable intake and hip fracture incidence in older men and women: the CHANCES Project. J Bone Miner Res 2016;31:1743-52. the official journal of the American Society for Bone and Mineral Research.

[21] Larsson SC, Bergkvist L, Wolk A. Long-term dietary calcium intake and breast cancer risk in a prospective cohort of women. Am J Clin Nutr 2009;89: 277-82.

[22] Willett WC, Howe GR, Kushi LH. Adjustment for total energy intake in epidemiologic studies. Am J Clin Nutr 1997;65. 1220S-8S; discussion 9S31S.

[23] Messerer M, Johansson SE, Wolk A. The validity of questionnaire-based micronutrient intake estimates is increased by including dietary supplement use in Swedish men. J Nutr 2004;134:1800-5.

[24] Michaelsson K, Melhus H, Warensjo Lemming E, Wolk A, Byberg L. Long term calcium intake and rates of all cause and cardiovascular mortality: community based prospective longitudinal cohort study. BMJ 2013;346:f228.

[25] Trichopoulou A, Costacou T, Bamia C, Trichopoulos D. Adherence to a Mediterranean diet and survival in a Greek population. N Engl J Med 2003;348: 2599-608.

[26] Tektonidis TG, Åkesson A, Gigante B, Wolk A, Larsson SC. A Mediterranean diet and risk of myocardial infarction, heart failure and stroke: a population-based cohort study. Atherosclerosis 2015;243:93-8.

[27] Knudsen VK, Fagt S, Trolle E, Matthiessen J, Groth MV, Biltoft-Jensen A, et al. Evaluation of dietary intake in Danish adults by means of an index based on food-based dietary guidelines. Food Nutr Res 2012;56.

[28] Bellavia A, Tektonidis TG, Orsini N, Wolk A, Larsson SC. Quantifying the benefits of Mediterranean diet in terms of survival. Eur J Epidemiol 2016;31: 527-30.

[29] Calltorp J, Adami HO, Astrom H, Fryklund L, Rossner S, Trolle Y, et al. Country profile: Sweden. Lancet (London, England) 1996;347:587-94.

[30] Gedeborg R, Engquist H, Berglund L, Michaelsson K. Identification of incident injuries in hospital discharge registers. Epidemiol 2008;19:860-7.

[31] VanderWeele TJ, Hernan MA, Robins JM. Causal directed acyclic graphs and the direction of unmeasured confounding bias. Epidemiol 2008;19: $720-8$.

[32] Orsini N, Bellocco R, Bottai M, Hagstromer M, Sjostrom M, Pagano M, et al. Validity of self-reported total physical activity questionnaire among older women. Eur J Epidemiol 2008;23:661-7. 
[33] Charlson ME, Pompei P, Ales KL, MacKenzie CR. A new method of classifying prognostic comorbidity in longitudinal studies: development and validation. J Chron Dis 1987;40:373-83.

[34] Quan H, Sundararajan V, Halfon P, Fong A, Burnand B, Luthi J, et al. Coding algorithms for defining comorbidities in ICD-9-CM and ICD-10 administrative data. Med Care 2005;43:1130-9.

[35] Harrell F. Regression modeling strategies with applications to linear models, logistic regression, and survival analysis. 1st ed. New York, USA: Springer; 2001.

[36] Nordic nutrition recommendations 2012. 5 ed. Copenhagen, Denmark: Nordic Council of Ministers, Nordic Council of Ministers; 2014.

[37] Rubin DB. Multiple imputation for nonresponse in surveys. John Wiley Sons; 1987.

[38] Fine JP, Gray RJ. A proportional hazards model for the subdistribution of a competing risk. J Am Stat Assoc 1999;94:496-509.

[39] Langdahl B, Ferrari S, Dempster DW. Bone modeling and remodeling: potential as therapeutic targets for the treatment of osteoporosis. Ther Adv Musculoskelet Dis 2016;8:225-35.

[40] Manolagas SC, Parfitt AM. What old means to bone. Trends Endocrinol Metabol 2010;21:369-74.

[41] Cerullo F, Gambassi G, Cesari M. Rationale for antioxidant supplementation in sarcopenia. J Aging Res 2012;2012:316943.

[42] Meng SJ, Yu LJ. Oxidative stress, molecular inflammation and sarcopenia. Int J Mol Sci 2010;11:1509-26.

[43] Sahni S, Mangano KM, McLean RR, Hannan MT, Kiel DP. Dietary approaches for bone health: lessons from the framingham osteoporosis study. Curr Osteoporos Rep 2015;13:245-55.

[44] Gaffney-Stomberg E. The impact of trace minerals on bone metabolism. Biol Trace Elem Res 2019;188:26-34.

[45] Movassagh EZ, Vatanparast H. Current evidence on the association of dietary patterns and bone health: a scoping review. Adv in Nutr (Bethesda, Md) $2017 ; 8: 1-16$.
[46] Malmir H, Saneei P, Larijani B, Esmaillzadeh A. Adherence to Mediterranean diet in relation to bone mineral density and risk of fracture: a systematic review and meta-analysis of observational studies. Eur J Nutr 2018;57: 2147-60.

[47] Trichopoulou A, Martínez-González MA, Tong TY, Forouhi NG, Khandelwal S, Prabhakaran D, et al. Definitions and potential health benefits of the Mediterranean diet: views from experts around the world. BMC Med 2014;12:112.

[48] Nieves JW. Skeletal effects of nutrients and nutraceuticals, beyond calcium and vitamin D. Osteoporos Int 2013;24:771-86.

[49] Garcia-Gavilan JF, Bullo M, Canudas S, Martinez-Gonzalez MA, Estruch R, Giardina S, et al. Extra virgin olive oil consumption reduces the risk of osteoporotic fractures in the PREDIMED trial. Clin Nutr 2018;37:329-35.

[50] Amcoff E, Edberg A, Enghardt Barbieri H, Lindroos A, Nälsén C, Pearson M, et al. Riksmaten - vuxna 2010-11, Livsmedels- och näringsintag bland vuxna i Sverige (Riksmaten adults 2010-11, Food and nutrient intakes among adults in Sweden). Uppsala, Sweden: Livsmedelsverket rapportserie; 2012.

[51] Michaelsson K, Wolk A, Langenskiold S, Basu S, Warensjo Lemming E, Melhus H, et al. Milk intake and risk of mortality and fractures in women and men: cohort studies. BMJ (Clinical research ed) 2014;349:g6015.

[52] Lau B, Cole SR, Gange SJ. Competing risk regression models for epidemiologic data. Am J Epidemiol 2009;170:244-56.

[53] Willett WC. Nutritional epidemiology. 3rd ed. New York: Oxford University Press; 2013.

[54] Michaelsson K, Wolk A, Byberg L, Mitchell A, Mallmin H, Melhus H. The seasonal importance of serum 25-hydroxyvitamin D for bone mineral density in older women. J Intern Med 2017;281:167-78.

[55] Reid IR, Bolland MJ. Controversies in medicine: the role of calcium and vitamin D supplements in adults. Med J Aust 2019;211:468-73.

[56] Harris H, Håkansson N, Olofsson C, Stackelberg O, Julin B, Åkesson A, et al. The Swedish mammography cohort and the cohort of Swedish men: study design and characteristics of two population-based longitudinal cohorts. OA Epidemiol 2013;1. 